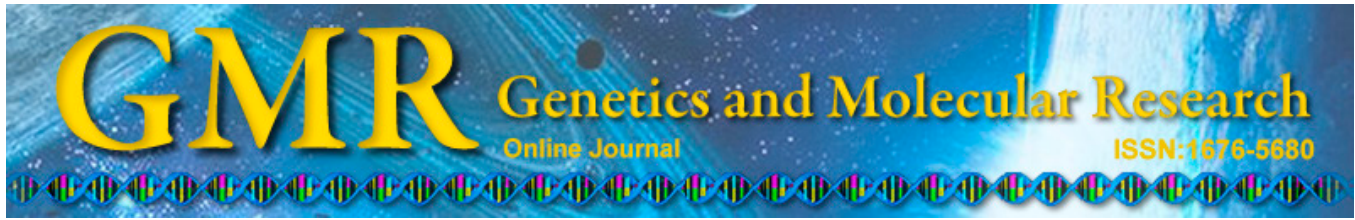

\title{
Comparative analysis of laparoscopic and ultrasound-guided biopsy methods for gene expression analysis in transgenic goats
}

\author{
C.H. Melo ${ }^{1,2}$, F.C. Sousa ${ }^{1}$, R.I.P.T. Batista ${ }^{1}$, D.J.D. Sanchez ${ }^{1}$, \\ J.M.G. Souza-Fabjan ${ }^{1}$, V.J.F. Freitas ${ }^{1}$, L.M. Melo ${ }^{1}$ and D.I.A. Teixeira ${ }^{1}$ \\ ${ }^{1}$ Laboratório de Fisiologia e Controle da Reprodução, \\ Faculdade de Medicina Veterinária, Universidade Estadual do Ceará, \\ Fortaleza, CE, Brasil \\ ${ }^{2}$ Laboratório de Biotecnologia e Reprodução Animal, \\ Curso de Medicina Veterinária, Instituto de Teologia Aplicada, \\ Sobral, CE, Brasil \\ Corresponding author: D.I.A. Teixeira \\ E-mail: darcioitalo@yahoo.com.br
}

Genet. Mol. Res. 14 (3): 8672-8684 (2015)

Received October 15, 2014

Accepted March 18, 2015

Published July 31, 2015

DOI http://dx.doi.org/10.4238/2015.July.31.16

\begin{abstract}
The present study aimed to compare laparoscopic (LP) and ultrasound-guided (US) biopsy methods to obtain either liver or splenic tissue samples for ectopic gene expression analysis in transgenic goats. Tissue samples were collected from human granulocyte colony stimulating factor (hG-CSF)-transgenic bucks and submitted to realtime PCR for the endogenous genes (Sp1, Baff, and Gapdh) and the transgene (hG-CSF). Both LP and US biopsy methods were successful in obtaining liver and splenic samples that could be analyzed by PCR (i.e., sufficient sample sizes and RNA yield were obtained). Although the number of attempts made to obtain the tissue samples was similar ( $\mathrm{P}$ $>0.05)$, LP procedures took considerably longer than the US method ( $\mathrm{P}$ $=0.03$ ). Finally, transgene transcripts were not detected in spleen or liver
\end{abstract}


samples. Thus, for the phenotypic characterization of a transgenic goat line, investigation of ectopic gene expression can be made successfully by LP or US biopsy, avoiding the traditional approach of euthanasia.

Keywords: Biopsy; Ultrasonography; Laparoscopy; Transgenesis; Tru-Cut; PCR

\section{INTRODUCTION}

Biotechnological applications of animal transgenesis are diverse and include the production of pharmaceuticals, generation of human and animal disease models, livestock improvement, and gene expression studies (Houdebine, 2000).

Several experiments have shown that the level and specificity of transgene expression cannot be easily predicted. For instance, DNA introduction by microinjection generates lines of animals expressing the foreign gene at different levels (Clark et al., 2000). In light of the recombinant protein being produced in the target tissue, the potential for systemic in vivo biological activity in the transgenic animal is a possibility and has previously been reported (Ko et al., 2000; Kim et al., 2006). Systemic activity of a foreign protein can be generated by unexpected events such as ectopic transgene expression or via a non-exocrine pathway of the protein from the target tissue to the blood (Rülicke and Hübscher, 2000; Dunn et al., 2005). In this context, investigation of ectopic gene expression in different tissues/organs is an important and unavoidable step to the phenotypic characterization of transgenic animals (Huang et al., 2012; Serova et al., 2012).

Investigations into ectopic gene expression in transgenic animals are typically performed with tissue samples collected after euthanasia of the specimens (Kong et al., 2009; Yin et al., 2012). However, this strategy has little relevance for transgenic livestock animals, which are usually limited in number. Thus, the development of alternative tissue collection methods to avoid euthanasia is necessary.

Apart from being slightly invasive, percutaneous biopsy is a promising approach as it is a well-established and routinely used procedure that is associated with low morbidity and small risks to the patient (Yu et al., 2001; Appelbaum et al., 2009; Saloura et al., 2010). Despite the technical variation with the clinical practice of this technique, (Duarte et al., 2009; Néspoli et al., 2010; Kassem et al., 2011) the traditional approach is the blind percutaneous needle biopsy.

With respect to intra-abdominal organs such as liver and spleen, a critical concern is how to safely obtain diagnostic-reliable tissue samples without performing a laparotomy (Zinzani et al., 1998; Lipp et al., 2010). In these cases, percutaneous biopsy can successfully be assisted by image-based techniques such as ultrasound (US) or laparoscopy (LP). Therefore, the aim of the current study was to compare LP and US-guided biopsy methods to collect reliable liver and splenic tissue samples for gene expression analysis in transgenic goats. First generation (F1) male bucks of a transgenic line for human granulocyte colony-stimulating factor (hG-CSF) milk expression previously produced by our group (Freitas et al., 2012) were used.

\section{MATERIAL AND METHODS}

\section{Animals and management}

This study was performed in the facilities of the Laboratory of Physiology and 
Control of Reproduction (LFCR), located in Fortaleza, Brazil, at $3^{\circ} 47^{\prime 3} 38^{\prime \prime S}$ (latitude) and $38^{\circ} 33^{\prime} 29^{\prime \prime} \mathrm{W}$ (longitude). All animal protocols were approved by the Animal Ethics Committee of Universidade Estadual do Ceará (CEUA/UECE No. 12237087-2) and Brazil's Biosafety Technical National Committee (CTNBio 228/06).

The experimental animals were six Canindé male goats, two of which were transgenic (T) for hG-CSF milk expression (F1 specimens of the 10M line described by Freitas et al., 2012) and four were non-transgenic (NT). The bucks aged 2-3 years old and showed body weights of $41.2 \pm 0.9 \mathrm{~kg}$ and a body condition score of $3.0 \pm 0.6(1-5 \mathrm{scale})$.

All animals were maintained under similar feeding and management conditions. Briefly, the males were raised under an intensive production system, receiving Tifton (Cynodon dactylon) hay in stalls. The diet was supplemented with commercial concentrate ( $18 \%$ crude protein). Water and mineralized salt were available ad libitum. It is noteworthy that before the start of the experiment, all animals were monitored and clinically evaluated.

\section{Biopsy}

Each animal was subjected to a biopsy procedure either by US-guided or by LP, at different times. Both biopsy methods were randomly performed at intervals of 15 days to obtain liver and splenic samples. In each procedure, the biopsies were repeated to obtain three tissue fragments of appropriate size to perform the subsequent steps. The time for performing each procedure, the number of biopsy attempts, and weight of the obtained fragment were recorded. Two NT bucks were not subjected to biopsy procedures being used as controls on behavioral assessments.

\section{US-guided biopsy}

All procedures for US biopsy were performed under strict aseptic conditions. The bucks were deprived of food and water for $24 \mathrm{~h}$ prior to the US-guided biopsy. All animals were subjected to a dissociative anesthetic protocol, which consisted of the im administration of $0.2 \mathrm{mg} / \mathrm{kg}$ body weight xylazine hydrochloride (Kensol, König, Avellaneda, Argentina), associated with the $\mathrm{im}$ administration of $10 \mathrm{mg} / \mathrm{kg}$ b.w. ketamine hydrochloride (Vetanarcol 5\%, König, Avellaneda, Argentina), and infiltrative local anesthesia with $2 \%$ lidocaine (Lidovet, Brasvet, Rio de Janeiro, Brazil).

For both organs, biopsy was guided by B-mode ultrasound connected to a $3.5 \mathrm{MHz}$ convex transducer. To obtain the hepatic fragment, the animals were contrained in the right lateral position and ultrasound of the liver tissue was carried out from the 7th to 12th intercostal space on the right flank. For splenic biopsy, the animals were placed in the left lateral position and sonographic identification of the spleen was carried out from the 8th to 12th intercostal space of the left flank. The biopsy sites were surgically prepared and the transducer positioned perpendicular to the ribs. A coaxial semi-automatic biopsy system (Achieve, Cardinal Health, USA) attached to the Tru-Cut type needle (14 G x $20 \mathrm{~cm}$ x 20 $\mathrm{mm}$ ) was introduced crossing the intercostal muscle and thus reaching the organ of interest. A biopsy route avoiding critical structures and major vessels was selected under ultrasound guidance. Tissue samples were weighed on an analytical balance and immediately stored at $-80^{\circ} \mathrm{C}$ until RNA extraction. 


\section{LP biopsy}

The bucks were deprived of food and water for $24 \mathrm{~h}$ prior to the LP. All LP biopsy procedures were performed under strict aseptic conditions. Anesthesia was induced by $i v$ administration of $20 \mathrm{mg} / \mathrm{kg}$ b.w. thiopental sodium (Tiopentax 2.5\%; Cristália, São Paulo, Brazil). After $5 \mathrm{~min}$, the goats were placed in dorsal recumbency with their legs tied to the surgical table, and $10 \%$ lidocaine spray (Xylestesin, Cristália), was administered in the oropharynx. The animals were intubated with an endotracheal tube with a cuff (Endotracheal Tube Solidor, Medic International Trading, Tianjin, China). Anesthesia was maintained by continuous infusion of $3 \%$ isoflurane (Isofrine; Cristália), using an inhalational system with medical oxygen (HB Hospitalar, São Paulo, Brazil). The airway pressure was maintained within $20 \mathrm{~cm}$ of water. The tracheal intermittent positive pressure of $10 \mathrm{~cm}$ of water, with oxygen flow of $1 \mathrm{~L} / \mathrm{min}$, an inspiration:expiration of $1: 2$, and a respiratory rate of 12 breaths per minute.

The ventral midline was taken as a basic laparoscopic surgical approach and pneumoperitoneum was conducted according to the technique described by Liem et al. (1994) and Kassem et al. (2011). A laparoscope (Storz, Tuttlingen, Germany) that was $5 \mathrm{~mm}$ in diameter, $35 \mathrm{~cm}$ in length, and had a straightforward Hopkins with $0^{\circ}$ viewing angle was used. Three ports were used: one optical and two $5 \mathrm{~mm}$ secondary ports including one operating port and one assisting port. The laparoscope passed through the cannula of the primary port and into the peritoneal cavity. A systemic examination of the entire abdominal cavity was done by a video camera connected to the eyepiece of the laparoscope and the images were transferred through the control unit to the TV monitor. A $360^{\circ}$ scan was performed for orientation and for determining if any trauma occurred from the cannula insertion. Secondary ports were inserted to allow the passage of accessory instruments used for the manipulation of abdominal viscera. To perform liver and splenic biopsies by LP, tertiary ports were inserted in locations that provided optimal access to the organ of interest. They were inserted while the laparoscope was removed, allowing a better evaluation of the trocar entering into the abdominal cavity. Once the desired organ (either liver or spleen) was observed, the same coaxial semi-automatic biopsy system attached to the Tru-Cut type needle was used, directing the needle above and perpendicular to the organ of interest in order to perform the puncture and fragment removal. Before cannula removal, pneumoperitoneum was removed by gentle massage and compression of the abdomen. Biopsy samples were weighed on an analytical balance and immediately stored at $-80^{\circ} \mathrm{C}$ until RNA extraction.

\section{Clinical examination and post-operative care}

Before the start of the experiment and during the eight experimental weeks, all animals were monitored daily. After the biopsy procedures were performed, the bucks were examined during the first $24 \mathrm{~h}$ (every $8 \mathrm{~h}$ ) to monitor any signs of pain, such as curvature of the back, difficulty of moving, and decreased appetite (Mellor et al., 2000). In order to quantify the intensity of the discomfort, a numerical scale varying from 0 to 2 ( 0 : signal absent, 1 : moderate signal manifestation, 2: intense signal manifestation) was attributed to each pain signal. The pain intensity (PI) for each animal was represented by the sum of the values attributed to all pain signals and could reach a maximum of $6(\mathrm{PI}=0-2$ : absent to mild pain, $\mathrm{PI}=2-4$ : mild to moderate pain and PI $=4-6$ : moderate to severe pain).

Additionally, the organs were submitted to ultrasonography before the procedures 
(T0) and at $24 \mathrm{~h}$ (T24) and $48 \mathrm{~h}$ (T48) after the biopsies, aiming to monitor morphological recovery and to assess potential echostructural changes. Simultaneously, measurements of rectal temperature $\left({ }^{\circ} \mathrm{C}\right)$, heart (beats per minute) and respiratory rates (breaths per minute), and ruminal movements $(\mathrm{N} / 3 \mathrm{~min})$ were also recorded.

\section{RNA extraction and reverse transcription}

Total RNA was prepared in triplicate from each sample using the RNeasy mini kit (Qiagen Science, Germantown, MD, USA) according to the manufacturer's instructions. Briefly, $600 \mu \mathrm{L}$ lysis buffer was added to the frozen sample and submitted to 2 cycles of 6.500 $\mathrm{Hz}$ in a Precellys 24 homogenizer (Precellys, Bertin Technologies, Montigny-le-Bretonneux, France). The lysates were diluted 1:1 with $70 \%$ ethanol and transferred to a spin column. After on-column DNase treatment, total RNA was eluted with $50-\mu \mathrm{L}$ RNase-free water. Reverse transcription was performed with $1 \mu \mathrm{L}$ Improm II (Promega, Madison, WI, USA) in manufacture's buffer, combined with $0.5 \mathrm{mM}$ dNTP (Promega), 40 U RNaseOUT (Invitrogen, Grand Island, NY, USA), and RNase-free water to make a final reaction volume of $20 \mu \mathrm{L}$. Reverse transcription was performed at $42^{\circ} \mathrm{C}$ for $60 \mathrm{~min}$, followed by enzyme inactivation at $70^{\circ} \mathrm{C}$ for $15 \mathrm{~min}$. The first strand cDNA was then stored at $-80^{\circ} \mathrm{C}$ for later use as the template in real-time PCR. Negative controls or RT blanks were prepared under the same conditions, but without the inclusion of reverse transcriptase.

RNA concentrations were accurately assessed by fluorimetry using the Qubit fluorimeter (Invitrogen) and Quant-iT RNA Assay Kit (Invitrogen), following the manufacturer's instructions. The yield of total RNA per tissue sample was expressed as $\mu \mathrm{g}$ RNA/mg tissue.

\section{Real-time PCR}

The PCR amplifications were performed in a Master-Cycler EP Realplex 4 S (Eppendorf AG, Hamburg, Germany). The cDNA from each group was run in triplicate for target and reference genes. For liver, the target gene was the $S p 1$ transcription factor, and for spleen, it was the B-cell activating factor (Baff). The reference gene was glyceraldehyde 3-phosphate dehydrogenase (Gapdh). hG-CSF expression was analyzed in both organs for T and NT animals. Each reaction consisted of a $20 \mu \mathrm{L}$ total volume containing $10 \mu \mathrm{L} 2$ X Power SYBR Green PCR Master Mix (Applied Biosystems, Foster City, CA, USA), $0.3 \mu \mathrm{M}$ of each primer, and $0.5 \mu \mathrm{L}$ cDNA. The qPCR protocol consisted of an initial incubation at $95^{\circ} \mathrm{C}$ for $10 \mathrm{~min}$, followed by 40 cycles of an amplification program of $95^{\circ} \mathrm{C}$ for $15 \mathrm{~s}, 55^{\circ} \mathrm{C}$ for $15 \mathrm{~s}$, and $60^{\circ} \mathrm{C}$ for $30 \mathrm{~s}$. Fluorescence data was acquired during the $60^{\circ} \mathrm{C}$ extension steps. Threshold and quantification cycle $(\mathrm{Cq})$ values were automatically determined by the Realplex 2.2 software (Eppendorf AG), using the default parameters. Melting curves were produced to assess amplification specificity by measuring the fluorescent signal at 10 -s intervals from $55-95^{\circ} \mathrm{C}$. To determine the linearity and the efficiency (E) of the PCR amplifications, standard curves were generated for each gene using serial dilutions of cDNA. The corresponding real-time PCR efficiencies were calculated from the given slopes (S) of the standard curves, according to the equation:

$$
\mathrm{E}=10^{(-1 / \mathrm{S})}-1
$$

Linearity was expressed as the square of the Pearson correlation coefficient $\left(\mathrm{R}^{2}\right)$. 


\section{Statistical analysis}

All of the results are reported as mean values \pm SEM and $P$ values less than 0.05 were considered to be statistically significant using the Prism 6.0 software (GraphPad Software Inc., La Jolla, CA, USA). For normality, the data were subjected to the Kolmogorov-Smirnov test. Parametric variables related to sample weight, time of procedure, and RNA yield were subjected to one-way analysis of variance (ANOVA) and the averages compared by the Student $t$-test. The number of biopsy attempts was subjected to the Mann-Whitney U-test. The relative quantification of the gene transcripts was performed using the $2^{-\Delta \Delta C t}$ method (Livak and Schmittgen, 2001). The PCR signal was normalized against Gapdh transcript levels. The differences in relative abundance of specific transcripts were compared using the Mann-Whitney U-test.

\section{RESULTS}

\section{Technical issues and clinical aspects}

The duration of food and water fasting was considered adequate for performing the surgical procedures, as there was no visceral distension and regurgitation of food during the biopsy. Furthermore, the anesthesia employed during each procedure and the associated use of lidocaine (local) was considered appropriate since the bucks showed no clinical signs of pain during the procedures. Regardless to the organ biopsied or technique used, none of the 16 procedures caused any complications that compromised buck survival and welfare. All clinical parameters were maintained within the reference values for the species throughout the observation period, and they are summarized in Table 1.

Table 1. Values of rectal temperature $\left({ }^{\circ} \mathrm{C}\right)$, heart frequency (beats per minute, bpm), respiratory frequency (breaths per minute, bpm), and ruminal movements (N/3 min) according to the groups, immediately after (T0), and at 24 (T24) and $48 \mathrm{~h}$ (T48) after the biopsy in transgenic and non-transgenic goats by using different biopsy methods (means $\pm \mathrm{SD}$ )

\begin{tabular}{|c|c|c|c|c|c|c|}
\hline \multirow[t]{2}{*}{ Group } & \multicolumn{3}{|c|}{ Liver biopsy } & \multicolumn{3}{|c|}{ Splenic biopsy } \\
\hline & T0 & $\mathrm{T} 24$ & T48 & T0 & $\mathrm{T} 24$ & T48 \\
\hline & & Temperature $\left({ }^{\circ} \mathrm{C}\right)$ & & & Temperature $\left({ }^{\circ} \mathrm{C}\right)$ & \\
\hline Ultrasound & $39.4 \pm 0.6$ & $39.6 \pm 0.5$ & $39.1 \pm 0.6$ & $38.4 \pm 1.3$ & $39.1 \pm 0.6$ & $39.5 \pm 1.1$ \\
\hline \multirow[t]{2}{*}{ Laparoscopic } & $39.5 \pm 0.4$ & $39.7 \pm 0.6$ & $39.3 \pm 0.6$ & $38.4 \pm 0.4$ & $38.8 \pm 0.2$ & $38.9 \pm 0.6$ \\
\hline & & Heart frequency & & & Heart frequency & \\
\hline Ultrasound & $104.0 \pm 23.6$ & $94.0 \pm 20.0$ & $99.0 \pm 15.4$ & $96.0 \pm 28.9$ & $100.0 \pm 25.5$ & $114.0 \pm 23.2$ \\
\hline Laparoscopic & $118.0 \pm 16.5$ & $\begin{array}{c}87.0 \pm 15.4 \\
\text { Respiratory frequency }\end{array}$ & $91.0 \pm 8.2$ & $98.0 \pm 18.0$ & $\begin{array}{c}98.0 \pm 5.2 \\
\text { Respiratory frequency }\end{array}$ & $95.5 \pm 12.7$ \\
\hline Ultrasound & $22.0 \pm 0.6$ & $19.0 \pm 2.0$ & $23.0 \pm 2.0$ & $23.5 \pm 11.1$ & $20.0 \pm 3.3$ & $22.0 \pm 4.0$ \\
\hline \multirow[t]{2}{*}{ Laparoscopic } & $24.0 \pm 5.7$ & $23.0 \pm 3.8$ & $25.0 \pm 10.5$ & $29.0 \pm 2.0$ & $18.0 \pm 2.3$ & $21.0 \pm 2.0$ \\
\hline & & Ruminal frequency (N/3min) & & & Ruminal frequency (N/3min) & \\
\hline Ultrasound & $2.5 \pm 0.6$ & $2.5 \pm 0.6$ & $2.8 \pm 0.5$ & $2.5 \pm 0.6$ & $2.3 \pm 0.5$ & $2.5 \pm 0.6$ \\
\hline Laparoscopic & $2.3 \pm 0.5$ & $2.5 \pm 0.6$ & $2.5 \pm 0.6$ & $2.5 \pm 0.5$ & $2.3 \pm 0.5$ & $2.8 \pm 0.5$ \\
\hline
\end{tabular}

With respect to the liver biopsy, the indirect visualization of the organ parenchyma by the US method was adequate to perform sample collection with minor difficulties, and was especially efficient when working at the 9th to 12th intercostal space. On the other hand, the LP method provided a clear visualization of the parietal face of the liver, which was important when trying to avoid multiple perforations and unnecessary bleeding. The main difficulties 
found during LP procedures were related to organ fixation with an atraumatic grasper, and to the need for maintenance of general anesthesia. Only the LP procedure allowed the observation of any potential bleeding in real-time. Regardless of the technique used, it was possible to obtain liver tissue samples in all procedures.

With respect to the spleen biopsy, and similar to the liver US biopsy, the US technique allowed for easy organ identification and collection of splenic fragments. Moreover, as was the case for the liver LP biopsy, the LP procedure provided total visual control of the abdominal cavity. The splenic LP biopsies possessed the same advantages and disadvantages as were identified for the hepatic biopsy by LP. Splenic tissue samples were obtained in all procedures using either technique.

\section{Liver biopsies}

Both LP and US biopsy methods allowed for the recovery of three tissue samples for real-time PCR analysis after a similar number of attempts $(\mathrm{P}>0.05 ; 1.1 \pm 0.2$ vs $1.1 \pm 0.2$, respectively). Furthermore, the surgical times were similar between the two procedures $(\mathrm{P}>$ $0.05 ; 13.7 \pm 2.5$ vs $10.0 \pm 1.5 \mathrm{~min}$, for LP and US procedures, respectively).

After the US procedure, $25 \%(1 / 4)$ of the animals presented PI $=1$ (absent or mild pain) whereas the remaining animals $(3 / 4)$ showed no signs of pain $(\mathrm{PI}=0)$. While performing LP biopsies, $50 \%(2 / 4)$ of the animals displayed PI $=1$ and the other half presented PI $=0$. Furthermore, for both biopsy methods no echostructural alteration was observed throughout the experimental period (Figure 1).

Tissue samples collected by LP and US procedures have similar average weights (P > $0.05 ; 21.7 \pm 1.3$ and $23.2 \pm 1.0 \mathrm{mg}$, for LP and US procedures, respectively), and yielded the same amount of total RNA $(1.0 \pm 0.3 v s 1.0 \pm 0.5 \mu \mathrm{g}$ RNA $/ \mathrm{mg}$ tissue for LP and US methods, respectively). In addition, $S p 1$ transcript levels did not differ between LP and US samples (P $>0.05$; Figure $2 \mathrm{~B}$ ). The PCR melting curves indicated that the amplifications were specific to the transcript of interest, and no amplification product was observed for the negative controls.

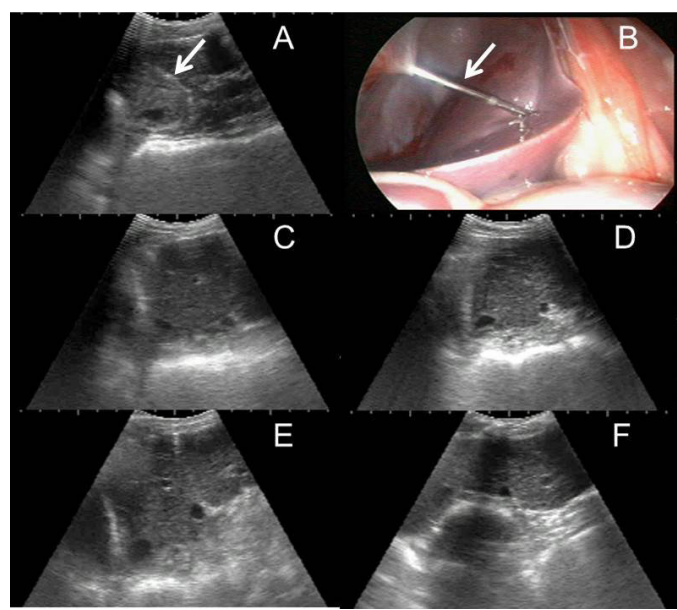

Figure 1. Liver biopsy methods in goats. A. C. E. Ultrasonographic images of the liver immediately before and 48 $\mathrm{h}$ after the ultrasound-guided biopsy. B. D. F. Ultrasonographic images of the liver immediately before and $48 \mathrm{~h}$ after a laparoscopic biopsy. The arrow shows the Tru-Cut needle. 
Spleen

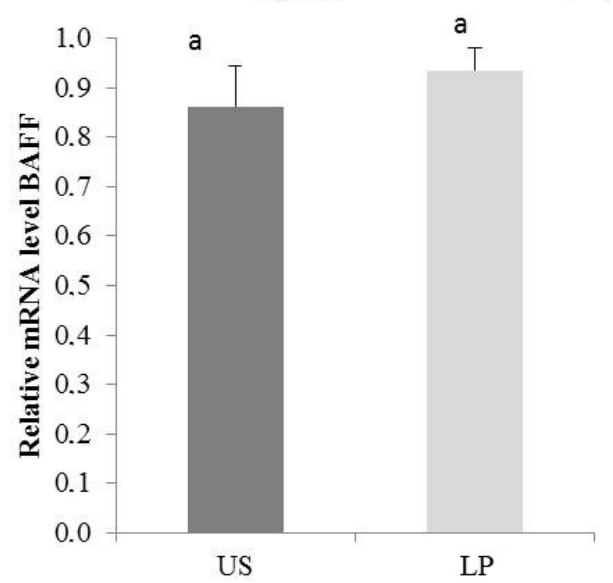

(A)

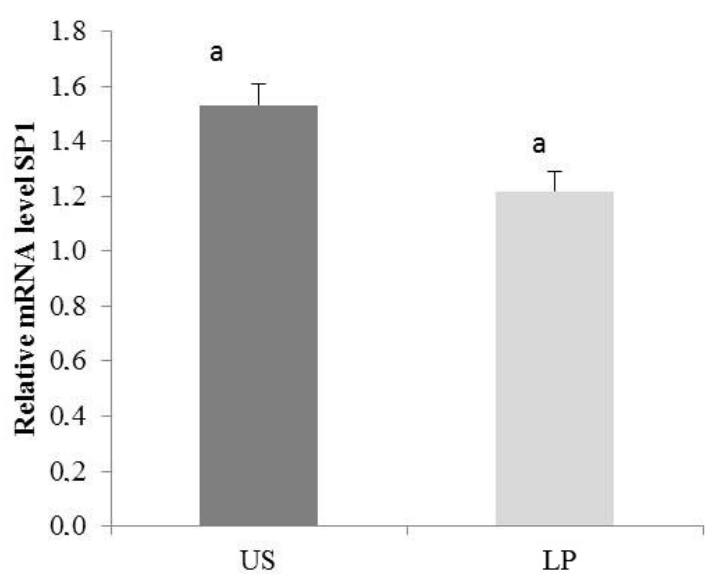

Figure 2. Real-time PCR analysis of Baff expression in spleen (A), and Spl expression in liver (B) obtained by different biopsy methods in goats. The fold differences in mRNA expression after normalization to the internal standard (Gapdh) are shown.

\section{Splenic biopsies}

Similar to that observed for the liver, both LP and US procedures allowed for the recovery of three splenic samples for real-time PCR after a similar number of attempts $(\mathrm{P}>$ $0.05 ; 1.3 \pm 0.4 v s 1.4 \pm 0.3$, respectively). However, LP procedures had a mean operative time that was significantly longer than the US procedures $(\mathrm{P}=0.03 ; 13.7 \pm 1.3 v \mathrm{~s} 9.2 \pm 0.9 \mathrm{~min}$, respectively). The highest PI was 1 for all animals in both methods. Thus, this PI value was calculated for $100 \%$ (4/4) of the animals submitted to a LP biopsy and for $50 \%(2 / 4)$ of the animals subjected to an US biopsy. The remaining animals (2/4) showed no signs of pain after the US biopsy technique. Furthermore, no echostructural alterations were observed in spleen after LP or US biopsies throughout the experimental period (Figure 3).

With respect to tissue fragment weight, LP and US biopsy methods have similar yields $(\mathrm{P}>0.05 ; 19.5 \pm 1.9$ vs $20.1 \pm 1.1 \mathrm{mg})$. Additionally, the yield of total RNA from the splenic tissue was comparable between the two biopsy methods $(0.4 \pm 0.04$ vs $0.5 \pm 0.05 \mu \mathrm{g}$ RNA/mg tissue for LP and US procedures, respectively). Finally, no differences were measured by realtime PCR in Baff transcript levels between splenic samples obtained by LP and US methods $(\mathrm{P}>0.05$; Figure 2A). Similar to that described for Sp1, the PCR melt curves indicated that the reactions were specific to the transcript of interest, and no amplicons were observed in the negative controls.

\section{Transgene expression}

It is noteworthy that transcript levels of hG-CSF were not detected in spleen or liver tissues, suggesting that no ectopic expression was present in these organs (Figure 4). As expected, amplification was not observed for the samples in which reverse transcriptase was not added (i.e., the negative controls). 


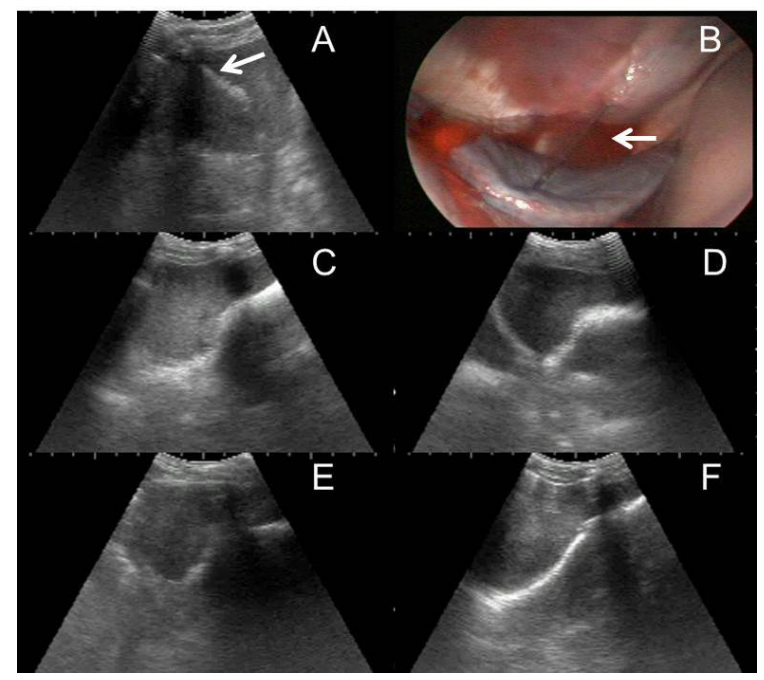

Figure 3. Splenic biopsy methods in goats. A. C. E. Ultrasonographic images of the spleen immediately before (T0) and $48 \mathrm{~h}$ (T48) after the ultrasound-guided biopsy. B. D. F. Ultrasonographic images of the spleen immediately before (T0) and $48 \mathrm{~h}$ (T48) after a laparoscopic procedure. The arrow shows the Tru-Cut needle.
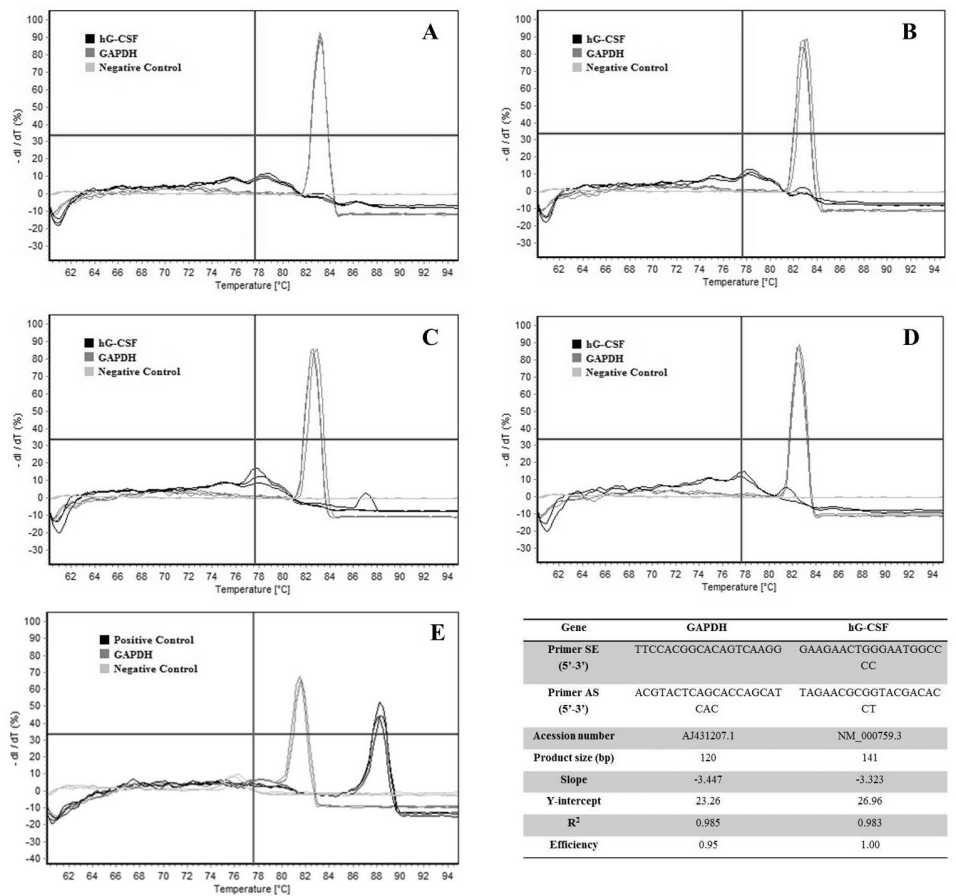

Figure 4. Liver transgene expression analysis by real-time PCR. Derivative melting curves of hG-CSF and Gapdh amplicons in non-transgenic (A and $\mathbf{B})$ and transgenic (C and $\mathbf{D})$ goats. Negative controls are assays containing complete PCR reagents without reverse transcriptase. Positive control (E) is the reaction with transcripts from human leukocytes. The curve slopes, efficiency, and linearity were calculated. The results for spleen gene expression are presented similarly to liver. 


\section{DISCUSSION}

This study has indicated that both US and LP biopsies were successful in obtaining tissue samples from goats that could be utilized for further molecular analyses. Moreover, both methodologies allowed for tissue sampling without significantly affecting animal welfare and comfort. In goats, there are few reports that describe biopsy techniques for soft tissues (Duarte et al., 2009; Kassem et al., 2011). In ruminants, most of the studies have been conducted on variations of the percutaneous biopsy technique (Harvey et al., 1984; Ferreira et al., 1996; Mølgaard et al., 2012). However, US (Lofstedt et al., 1988; Néspoli et al., 2010) or LP biopsies (Phillippo, 1973; Duarte et al., 2009; Kassem et al., 2011) have been quite unexplored, even with their recognized accuracy and safety.

The liver biopsies conducted in this study had a lower (not significant) average surgical time for US ( $10 \mathrm{~min})$ as compared to LP $(13 \mathrm{~min})$ procedures. A previous study with goats subjected to liver laparoscopic biopsies produced average surgery times of $23 \mathrm{~min}$ (Duarte et al., 2009). Thus, the surgical procedures conducted in this study were comparable, if not superior to those reported previously.

The average number of attempts needed to obtain a liver fragment was approximately 1.1 for both methods, which is similar to the 1.0 (US) and 1.1 (LP) attempts needed to biopsy sheep liver as described by Néspoli et al. (2010). The Tru-Cut needle allowed for the recovery of repeated tissue samples. In our perspective, one of the main factors that contributed to the success of the biopsies was the semi-automatic mechanism of the needle cannula. This system reduced the need to repeat the technique to assure the recovery of larger samples than those obtained with the manual Tru-Cut needles (Hoope et al., 1986).

Regardless of the biopsy method used, all liver samples were of a uniform weight. Furthermore, the results obtained are consistent with those of percutaneous liver biopsies performed with the same type of needle (Harvey et al., 1984; Ferreira et al., 1996; Néspoli et al., 2010). Confirming previous reports, the amount of blood observed from the liver biopsies was considered clinically irrelevant (Fantinatti et al., 2003; Duarte et al., 2009). Hence, no alterations were observed to the physical condition of the goats following their physical examination (Table 1), and the condition of the animals was considered normal for goats. Moreover, the ultrasound examination after the procedure demonstrated an organ with defined contours, homogeneous and hypoechoic echotexture (Figure 1). With respect to animal pain during either biopsy method, no buck showed signs of moderate or severe pain.

For the splenic biopsies, the average surgical time for the US procedure ( $\sim 9 \mathrm{~min})$ was significantly lower than that of the LP procedure (14 min). The longer duration of the LP procedure was associated with the fact that transumbilical access to the organ was difficult given the large amount of viscera overlapping the organ.

In the current study, the average number of attempts needed to obtain a splenic fragment was approximately 1.4 for both biopsy methods. In a general way, splenic biopsy aspiration is more indicated than the Tru-Cut needle due to the risk of bleeding in men and animals (Christopher, 2003). However, our study demonstrated that in goats, the biopsy techniques used were safe and easy to perform, needing only few attempts to obtain a usable fragment.

The average weight of the splenic fragments obtained was approximately $20 \mathrm{mg}$. Sample weight varies directly with the type and caliber of the biopsy instrument, however for splenic biopsy there are no reports in the literature describing the expected sample weight. One principle concern with the splenic biopsies was the increased possibility of bleeding. 
However, this complication depends on the size and number of samples obtained, the probability of vessel damage, the nature of the pathology, as well as the location of the lesion. As was the case in dogs, cats, and humans (Christopher, 2003), our results demonstrate that the amount of bleeding was not a limiting factor for the execution of splenic biopsies. Ultrasonographic evaluations demonstrated that the spleen maintained its homogeneous echotexture and was hyperechoic as compared with the cortical left kidney and liver (Figure 3).

Often postoperative behavioral changes in an animal may indicate pain (Dobromylskyj et al., 2000). For instance, in cattle, following a percutaneous needle liver biopsy (under local anesthesia), they presented increased restlessness, head shaking, and decreased rumination, which possibly indicated pain (Mølgaard et al., 2012). It is important to highlight that in the current study no behavioral changes were identified.

Spl transcripts were successfully detected in liver and no significant differences were observed between US or LP biopsy methods. There is emerging evidence to indicate that SP proteins play a key role in regulating nuclear signaling elicited by hormones other than insulin (Solomon et al., 2008). Sp1 may be more directly involved in the regulation of insulin signaling via its role in regulating the transcription of the insulin receptor gene (Fukuda et al., 2001; Copland et al., 2007). Given this fact, Sp1 and its related proteins have the potential to be involved in hyperinsulinemia and obesity, which are associated with the metabolic syndrome.

In the current study, Baff transcripts were successfully detected in biopsied spleen samples, however no statistically significant differences were found between the two biopsy methods used. Based on previous studies, Baff is mainly produced by innate immune cells such as macrophages/monocytes, neutrophils, dendritic cells, activated T cells, and malignant B cells, as well as by non-lymphoid cells like epithelial cells (Mackay et al., 2007; Mackay and Schneider, 2009). Several lines of evidence indicate that Baff plays an important role not only in B cell survival, but also in B cell maturation and diversification, including IgG and IgA class switching (Cerutti and Chen, 2010). Moreover, it is now clear that Baff can also modulate $\mathrm{T}$ cell function in vitro and in vivo (Mackay and Leung, 2006).

In the current study, hG-CSF transcript levels were not detected in liver or spleen samples, indicating that the $\mathrm{T}$ goats possessed no ectopic hG-CSF expression in these organs. Tissue-specific secretion of hG-CSF into the milk of transgenic mice ranged from approximately $19-40 \mu \mathrm{g} / \mathrm{mL}$. RT-PCR analysis of various tissues of transgenic mice demonstrated that hG-CSF was detected solely in the mammary glands of the progeny of all founders (Serova et al., 2012).

The importance of fasting prior to a biopsy has been emphasized previously (Duarte et al., 2009; Néspoli et al., 2010), as inappropriate fasting can cause the regurgitation of food during the biopsy. For instance, sheep subjected to a laparoscopy after fasting for $72 \mathrm{~h}$ and water deprivation for $24 \mathrm{~h}$ regurgitated rumen contents because of pneumoperitoneum and intravenous anesthesia with ketamine and acepromazine (Bittencourt et al., 2004). In our study, this complication was not observed, which suggests that appropriate fasting times and anesthetic protocols were used for each procedure.

In conclusion, US and LP liver and spleen biopsies were effective in obtaining tissue fragments that were viable for gene expression analyses without compromising goat health and welfare. Furthermore, analysis of the biopsied samples indicated that the transgenic goats do not possess ectopic expression of hG-CSF in the liver or spleen. Such results support the unnecessary use of euthanasia for gene expression investigations in transgenic animals. It is important to highlight that all experimental animals were still healthy at the time of publication. 


\section{Conflicts of interest}

The authors declare no conflict of interest.

\section{ACKNOWLEDGMENTS}

The authors wish to thank LFCR and staff for their support and placing all the facilities at our disposal. This research was supported by Comissão de Aperfeiçoamento de Pessoal do Nível Superior (CAPES), Fundação Cearense de Apoio ao Desenvolvimento Científico e Tecnológico (FUNCAP), and Conselho Nacional de Desenvolvimento Científico e Tecnológico (CNPq).

\section{REFERENCES}

Appelbaum L, Kane RA, Kruskal JB, Romero J, et al. (2009). Focal hepatic lesions: US-guided biopsy-lessons from review of cytologic and pathologic examination results. Radiology 250: 453-458.

Bittencourt RHFPM, Silva MC, Moreira VMS, Sousa SKSA, et al. (2004). Observações sobre o uso de cetamina, acepromazina e halotano em ovelhas submetidas a procedimentos laparoscópicos. (Observations about the use of ketamin, acepromazine and halothane in ewes subjected to laparoscopic procedures). Rev. Bras. Med. Vet. 26: 150-154.

Cerutti A and Chen K (2010). Role of BAFF and APRIL in antibody production and diversification. In: BLyS Ligands and Receptors (Cancro MP, eds.). Humana Press, Pennsylvania, 65-92.

Christopher MM (2003). Cytology of spleen. Vet. Clin. North Am. Small Anim. Pract. 33: 135-152.

Clark AJ, Burl S, Denning C and Dickinson P (2000). Gene targeting in livestock: a preview. Transgenic Res. 9: 263-275.

Copland JA, Pardini AW, Wood TG, Yin D, et al. (2007). IGF-1 controls GLUT3 expression in muscle via the transcriptional factor Sp1. Biochim. Biophys. Acta 1769: 631-640.

Dobromylskyj P, Flecknell PA, Lascelles DB, Pascoe PJ, et al. (2000). Pain assessment. In: Pain Management in Animals (Flecknell P and Waterman-Pearson A, eds.). W.B. Saunders, Glasgow, 53-79.

Duarte ALL, Cattelan JW, Bezerra MB, Vicente WRR, et al. (2009). Videolaparoscopic guided hepatic biopsy with tru-cut needle in goats. Arq. Bras. Med. Vet. Zootec. 61: 12-19.

Dunn DA, Pinkert CA and Kooyman DL (2005). Foundation Review: Transgenic animals and their impact on the drug discovery industry. Drug Discov. Today 10: 757-767.

Fantinatti AP, Daleck CR, Nunes N, Alessi AC, et al. (2003). Laparoscopy hepatic biopsy through cauterization. Ciênc. Rur. 33: 703-707.

Ferreira AV, Van der Merwe HJ and Slippers SC (1996). A technique for obtaining liver biopsies from mature sheep. Small Rumin. Res. 22: 89-92.

Freitas VJF, Serova IA, Moura RR, Andreeva LE, et al. (2012). The establishment of two transgenic goat lines for mammary gland hG-CSF expression. Small Rumin. Res. 105: 105-113.

Fukuda H, Noguchi T and Iritani N (2001). Transcriptional regulation of insulin receptor gene promoter in rat hepatocytes. Biochem. Biophys. Res. Commun. 280: 1274-1278.

Harvey RB, Lovering SL, Bailey EM and Norman JO (1984). The influence of multiple liver biopsies on hematologic and serum biochemical values of sheep. Cornell Vet. 74: 322-330.

Hoope FE, Hager DA, Poulos PW, Ekman S, et al. (1986). A comparison of manual and automatic ultrasound-guided biopsy techniques. Vet. Radiol. 27: 99-101.

Houdebine LM (2000). Transgenic animal bioreactors. Transgenic Res. 9: 305-320.

Huang J, Xiong Y, Li T, Zhang L, et al. (2012). Ectopic overexpression of swine PPAR $\gamma 2$ upregulated adipocyte genes expression and triacylglycerol in skeletal muscle of mice. Transgenic Res. 21: 1311-1318.

Kassem MM, el-Gendy SA, Abdel-Wahed RE and el-Kammar M (2011). Laparoscopic anatomy of caprine abdomen and laparoscopic liver biopsy. Res.Vet. Sci. 90: 9-15.

Kim MO, Kim SH, Lee SR, Kim KS, et al. (2006). Transgene expression of biological active recombinant human granulocyte-colony stimulating factor (hG-CSF) into mouse urine. Life Sci. 78: 1003-1009.

Ko JH, Lee CS, Kim KH, Pang MG, et al. (2000). Production of biologically active human granulocyte colony stimulating factor in the milk of transgenic goat. Transgenic Res. 9: 215-222.

Kong Q, Wu M, Huan Y, Zhang L, et al. (2009). Transgene expression is associated with copy number and cytomegalovirus promoter methylation in transgenic pigs. PLoS One 4: 1-10. 
Liem T, Applebaum $\mathrm{H}$ and Herzberger B (1994). Hemodynamic and ventilatory effects of abdominal $\mathrm{CO}_{2}$ insufflation at various pressures in young swine. J. Pediatr. Surg. 29: 966-969.

Lipp MJ, D'Souza LS, Clain DJ, Bodenheimer HC Jr, et al. (2010). Trends in the indication and method of liver biopsy for hepatitis B and C. Dig. Dis. Sci. 55: 2971-2976.

Livak KJ and Schmittgen TD (2001). Analysis of relative gene expression data using real-time quantitative PCR and the 2(-Delta Delta C(T)) method. Methods 402-408.

Lofstedt J, Schelling S, Stowater J and Morris E (1988). Antemortem diagnosis of hepatic adenocarcinoma in a ewe. $J$. Am. Vet. Med. Assoc. 193: 1537-1538.

Mackay F and Leung H (2006). The role of the BAFF/APRIL system on T cell function. Semin. Immunol. 18: 284-289.

Mackay F and Schneider P (2009). Cracking the BAFF code. Nat. Rev. Immunol. 9: 491-502.

Mackay F, Silveira PA and Brink R (2007). B cells and the BAFF/APRIL axis: fast-forward on autoimmunity and signaling. Curr. Opin. Immunol. 19: 327-336.

Mellor DJ, Cook CJ and Stafford KJ (2000). Quantifying some responses to pain as a stressor. In: The Biology of Animal Stress - Basic Principles and Implications for Animal Welfare (Moberg GP and Mench J, eds.). CABI Publishing, Wallingford, 171-198.

Mølgaard L, Damgaard BM, Bjerre-Harpøth V and Herskin MS (2012). Effects of percutaneous needle liver biopsy on dairy cow behaviour. Res. Vet. Sci. 93: 1248-1254.

Néspoli PB, Gheller VA, Peixoto PV, França TN, et al. (2010). Evaluation of techniques for liver biopsy in sheep. Pesq. Vet. Bras. 30: 29-36.

Phillippo M (1973). A technique for liver biopsy in sheep. J. Agric. Sci. 80: 313-314.

Rülicke T and Hübscher U (2000). Special Review Series-Gene Manipulation and Integrative Physiology Germ line transformation of mammals by pronuclear microinjection. Experim. Physiol. 85: 589-601.

Saloura EA, Bizimi V, Theodoropoulos E, Motogna-Kalokairinou M, et al. (2010). Focal hepatic lesion ultrasound-guided biopsies. Med. Ultrason. 12: 295-299.

Serova IA, Dvoryanchikov GA, Andreeva LE, Burkov IA, et al. (2012). A 3,387 bp 5'-flanking sequence of the goat alpha-S(1)-casein gene provides correct tissue-specific expression of human granulocyte colony-stimulating factor (hG-CSF) in the mammary gland of transgenic mice. Transgenic Res. 21: 485-98.

Solomon SS, Majumdar G, Hernandez AM and Raghow R (2008). A critical role of Sp1 transcription factor in regulating gene expression in response to insulin and other hormones. Life Sci. 83: 305-312.

Yin Z, Kong QR, Zhao ZP, Wu ML, et al. (2012). Position effect variegation and epigenetic modification of a transgene in a pig model. Genet. Mol. Res. 11:355-369.

Yu SC, Liew CT, Lau WY, Leung TW, et al. (2001). US-guided percutaneous biopsy of small $(<$ or $=1-\mathrm{cm})$ hepatic lesions. Radiology 218: 195-199.

Zinzani PL, Colecchia A, Festi D, Magagnoli M, et al. (1998). Ultrasound-guided core-needle biopsy is effective in the initial diagnosis of lymphoma patients. Haematologica 83: 989-992. 